\title{
Messages in Sensory Nerve Fibres and their Interpretation.*
}

$B^{\mathrm{Y}}$ amplifying the electric changes which take place in the individual nerve fibres it is possible to record the messages which pass from the sense organs to the central nervous system and from the motor nerve cells to the muscles. It is found that a series of brief potential changes travel along each nerve fibre; the changes are of fixed intensity and duration, but their frequency varies with the intensity of the excitation. Each potential change represents a nerve impulse of the type made familiar by the classical methods of electro-physiology. Reasons are given for the belief that all nervous communication is carried out by such impulse messages, and that the impulses, like the electric changes which accompany them, are unaffected by variations in the intensity of the stimulus. The general similarity of motor and sensory messages makes it probable that the sensory nerve endings and the synaptic regions of the central nervous system work on a common plan depending on the fundamental properties of excitable cells.

The sensory messages which have been most thoroughly investigated are those produced by the muscle spindles. Those from the skin receptors are less easy to analyse but are of greater interest to the physiology of sensation. At present the most definite results have been obtained from the frog. The frog's

* Abstract of the Croonian Lecture delivered beforc the Royal Society on June 4 by Prof. E. D. Adrian, F.R.S. skin contains receptors which respond to light contact with a brief discharge of impulsos travelling in nerve fibres which conduct rapidly. A vibrating stimulus gives a series of impulses with the same frequency as that of the stimulus, but discharges of high frequency and long duration from these receptors do not give rise to pain. Stimuli which would be likely to cause continued pain give rise to impulses of small action potential travelling in fibres which conduct very slowly (about 1 metre a second).

In the mammal, as in the frog, light touch produces a brief discharge of impulses of large potential conducted rapidly, and firm prossure gives a continued discharge. Impulses of smaller potential conducted at slower rates are produced by movement of the skin, and porsistent discharges often arise from exposed tissues. At present it appears that some of these im. pulses are caused by stimuli which would not necessarily be painful.

A comparison of these results with those of Gasser and Erlanger and of Pioron shows that the nerve fibres responsible for pain are not all of the same type, though they are all of smaller diameter than the tactile fibres. It is suggested that the rate of reaction and amount of convergence in the sensory pathways are important factons in determining the intensity of sensation, since this must depend on a summation of the effects of discontinuous impulses.

\section{Fisheries Research at Hull.}

THE Department of Zoology in the University College of Hull has recently been expanded into that of Zoology and Oceanography. From its first establishment it has been intended that there should be co-operation between the Department of Zoology and the fishing industry. The Humber ports form the largest fishing centre in the world. The Council of the College has now decided to put into operation a scheme of fishery researeh which is to be organised by Prof. A. C. Hardy. A new section will be added to the accommodation of the department and three research biologists will be appointed. The capital expenditure will be borne by the College, but the greater part of the maintenance charges will be met by a grant from H.M. Treasury, which has been made on the recommendation of the Development Commissioners. A grant towards the cost has also been made by the Fishmongers' Company, and it is hoped that contributions will be made by the fishing industry itself. The scheme of research, which will be carried out in co-operation with the Ministry of Agriculture and Fisheries and the Fishery Board for Scotland, and will be co-ordinated with the researches of the International Council for the Exploration of the Sea, concerns the distribution of the North Sea plankton in relation to the movements of fish, particularly the herring.

It is the policy of the department to carry out this research not from a single research ship, but from fishing vessels and other commercial ships which are prepared to carry specially designed self-recording instruments for plankton and other measurements. It is believed that there are certain important problems connected with our knowledge of the sea and its changing conditions which cannot be solved by using one research ship to cruise over the area concerned, just as a knowledge of the weather cannot be obtained by having one meteorological station moving about from place to place. It is proposed to chart in broad outline the monthly movements of the North Sea plankton by the simultaneous use of continuous plankton recorders on a number of scheduled steamship routes across the North Sea, and to correlate the distribution of the plankton with the concentration of fish as reported by the industry. The herring shoals do not always turn up where they are expected; they move their ground from time to time; usually the fishermen can find them, but sometimes they cannot, at any rate in sufficient numbers to mako a successful season. When, over a period of five years, a knowledge has been gained of the changing distribution of herring food and patches of such organisms as Phoeocystis and Rhizosolenia, which the herring apparently avoid, it is hoped that it may be possible to make forecasts as to the position of the shoals of herring. From this work a wider field of investigations should be opened up, including a study of the possible causes underlying the fluctuations in the stocks of different fish.

A new continuous plankton recorder suitable for use on commercial ships has been designed; it is an improvement on, and a smaller pattern than, the original machine which was first used on the 1925-27 Discovery Expedition and was described in NATURE of Oct. 30, 1926. It is towed like a paravane behind a ship and continually samples the plankton in the water traversed. The plankton is collected on a long banding of fine silk netting which winds into a preservation chamber. It is worked from the water by a propeller, the adjustable blades of which allow each of a series of numbered divisions on the moving silk to represent a mile or more of sea. The rolls obtained are kept for examination on a special microscope substage.

A number of simpler instruments, obtaining a single sample of the plankton for correlation with the catch of herrings, will be used by herring drifters when engaged in fishing.

In addition to the research programme, a one-year course in oceanography with particular reference to fishery problems is being arranged for post-graduate students. 